\title{
Ectopic cilia associated with an orbital dermoid cyst and sinus tract: case report
}

\author{
*David Krahulík, MD, PhD, ${ }^{1}$ Marta Karhanová, MD, PhD, ${ }^{2}$ Miroslav Vaverka, MD, PhD, ${ }^{1}$ \\ Světlana Brychtová, $\mathrm{MD}, \mathrm{PhD},{ }^{3}$ and Dagmar Pospíšilová, $\mathrm{MD}, \mathrm{PhD}^{4}$ \\ Departments of ${ }^{1}$ Neurosurgery, ${ }^{2}$ Ophthalmology, ${ }^{3}$ Clinical and Molecular Pathology, and ${ }^{4}$ Pediatrics, University Hospital Olomouc, \\ Czech Republic
}

\begin{abstract}
Ectopic cilia are extremely rare congenital anomalies in which eyelash follicles appear in an abnormal place on the eyelid, most typically on the lateral quadrant of the anterior surface of the upper eyelid. In the majority of cases, simple surgical excision of ectopic cilia is indicated because of its cosmetic aspect. There is usually no associated medical comorbidity with this anomaly. The authors report an unusual case of ectopic cilia associated with an orbital dermoid cyst and sinus tract. A 3-year-old boy was initially diagnosed with ectopic cilia on the left upper eyelid. There was no history of inflammation or swelling of the eyelid. An ophthalmological examination revealed only $1 \mathrm{~mm}$ of ptosis; no proptosis, inferior displacement, or palpable orbital mass was present. During surgical excision of the ectopic cilia, a thin sinus tract was identified, leading posteriorly to the orbit. Magnetic resonance imaging performed after the excision showed a supraorbital extraconal mass just below the roof of the left orbit. A supraorbital 2-piece craniotomy was performed with total extirpation of the dermoid cyst. The cyst was removed en bloc without damage to the extraocular muscles, but the sinus tract could no longer be identified. Follow-up MRI was performed 6 months after surgery and showed no evidence of recurrence. A follow-up ophthalmological examination showed no signs of inferior displacement or proptosis. To the best of the authors' knowledge, this case is the first reported instance of ectopic cilia associated with a dermoid cyst and sinus tract in which no typical clinical signs and symptoms of possible orbital pathology were present. This case highlights the value of radiological examination in all cases of ectopic cilia prior to surgical excision.
\end{abstract}

http://thejns.org/doi/abs/10.3171/2014.12.PEDS14512

KEY WORDS ectopic cilia; dermoid cyst; orbit; sinus tract; congenital

$\mathrm{E}$ СтоРIC cilia are extremely rare congenital anomalies in which eyelash follicles appear in an abnormal place on the eyelid, most typically on the lateral quadrant of the anterior surface of the upper eyelid. There is usually no associated medical comorbidity with this anomaly. In the majority of cases, simple surgical excision is indicated because of its cosmetic aspect. We present a case of a patient with ectopic cilia and associated dermoid cyst with sinus tract in which no clinical signs of a possible presence of orbital pathology were present at the time of the diagnosis. This case report highlights the value of radiological examination prior to surgical excision of ectopic cilia to discover this rare finding.

\section{Case Report}

History and Examination

A 3-year-old boy presented to the Department of Ophthalmology with a cluster of dark hairs on the lateral quadrant of the anterior surface of his left upper eyelid (Fig. 1). There was no history of inflammation or swelling of the eyelid and his medical history was unremarkable. No positive family history of any eye abnormalities was noted. An ophthalmological examination revealed $1 \mathrm{~mm}$ of ptosis, with the remainder of the examination showing normal results. No proptosis, inferior displacement, or palpable orbital mass was present. His general physical examination was

SUBMITTED September 26, 2014. ACCEPTED December 31, 2014

INCLUDE WHEN CITING Published online May 15, 2015; DOI: 10.3171/2014.12.PEDS14512.

DISCLOSURE The authors report no conflict of interest concerning the materials or methods used in this study or the findings specified in this paper.

* Drs. Krahulík and Karhanová contributed equally to this work. 


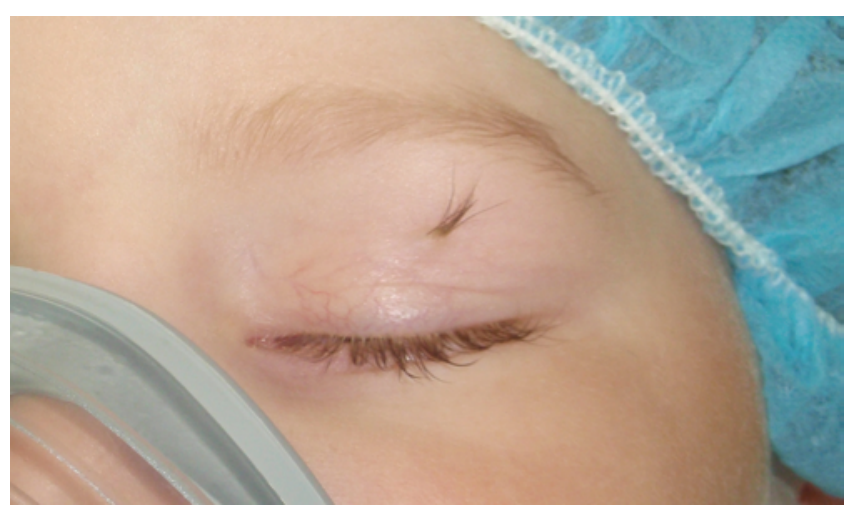

FIG. 1. Photograph showing a cluster of dark hairs on the lateral quadrant of the anterior surface of the left upper eyelid, a typical clinical picture of ectopic cilia. Figure is available in color online only.

normal, and no other associated abnormality was detected. The diagnosis of ectopic cilia was made and surgical excision was indicated specifically for cosmetic reasons. During the surgical excision of the ectopic cilia under general anesthesia, a thin fibrous band leading posteriorly to the orbit was detected. The band was excised after reaching the end of the band posteriorly. A small amount of oily liquid was released and a tiny sinus tract was clearly identified, but additional posterior dissection was not possible from the anterior approach. Histopathological examination of the excised material was completely consistent with the diagnosis of ectopic cilia when an abnormally arranged cluster of 12 hair follicles embedded in a desmoplastic stroma was found, without signs of inflammation. Four follicles had the appearance of an anagen phase of the hair growth cycle, and the remaining ones were formed by hair bulbs, with some of them miniaturized. There were also 2 small sebaceous glands in the lesion (Fig. 2).

\section{Operation and Postoperative Course}

Three months after excision of the ectopic cilia, a stiff

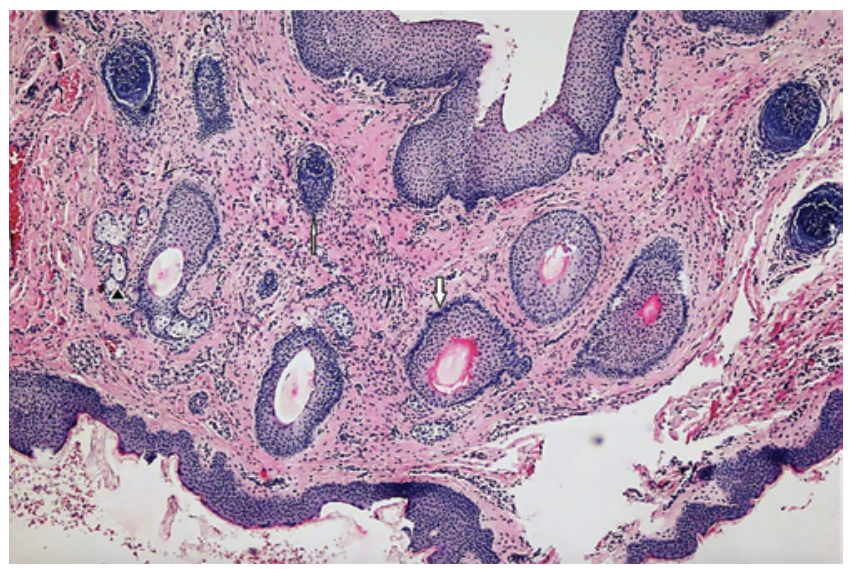

FIG. 2. Photomicrograph showing an abnormally arranged cluster of hair follicles embedded in a desmoplastic stroma, without signs of inflammation. The follicles have an appearance of the anagen phase of the hair growth cycle, with the hair shaft in the center (wide arrow); there are also hair bulbs, some of them miniaturized (thin arrow). Close to the follicles, there are small sebaceous glands (triangle). $\mathrm{H} \& \mathrm{E}$, original magnification $\times 100$. Figure is available in color online only.

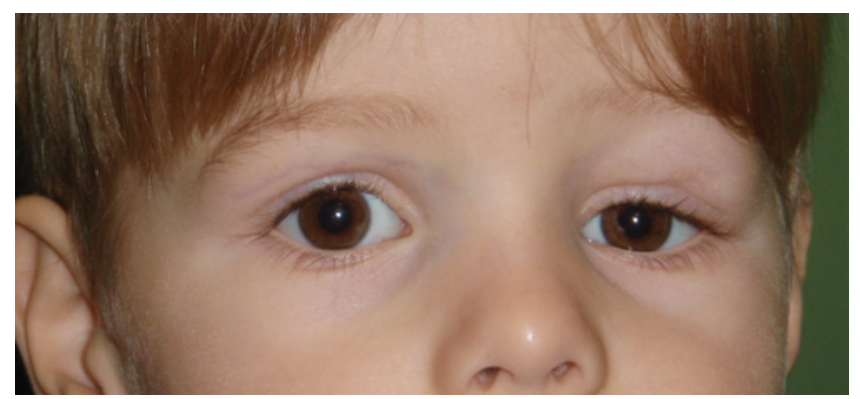

FIG. 3. Photograph obtained 3 months after excision of the ectopic cilia showing a stiff edema of the upper eyelid, $3 \mathrm{~mm}$ of ptosis, and mild inferior displacement of the globe. Figure is available in color online only.

edema of the upper eyelid, $3 \mathrm{~mm}$ of ptosis, and mild inferior displacement of the globe were present (Fig. 3). Magnetic resonance imaging showed a supraorbital extraconal mass just below the roof of the left orbit. The size of the mass was $30 \times 25 \times 15 \mathrm{~mm}$ and the signal of the presented mass was heterogeneous on T1- and T2-weighted MR images, with slight enhancement of the margins after contrast agent administration (Fig. 4). On preoperative laboratory examination, a prolonged activated partial thromboplastin time was found and, in a detailed investigation, deficiency of von Willebrand factor was diagnosed. The patient was prepared for operation with an infusion of a high-purity factor VIII concentrate (antihemophilic factor/von Willebrand factor complex [Humate-P]; CSL Behring). A supraorbital 2-piece craniotomy was performed with total extirpation of the dermoid cyst. The cyst was removed en bloc without damage to the extraocular muscles, but the tiny sinus tract could no longer be identified. The specimen was $35 \mathrm{~mm}$ in length, and inside, beneath the membrane, yellow content was visible. Microscopically, a typical dermoid cyst was observed containing sebaceous glands, hairs, and hair follicles (Fig. 5).

Follow-up MRI performed 6 months after surgery showed no evidence of recurrence. A follow-up ophthalmological examination showed $1 \mathrm{~mm}$ of ptosis, but no signs of inferior displacement or proptosis.

\section{Discussion}

The first report of ectopic cilia was published by Wiegmann $^{25}$ in 1936, in a 5-year-old girl. The presentations published in the literature fall into 2 distinct categories: congenital ectopic cilia situated externally protruding from the anterior surface of the tarsal plate away from the lid margin, 3,6,14,19 and posterior cilia acquired later in life emerging from the tarsal conjunctiva. ${ }^{11,13}$ Almost 20 cases of cutaneous ectopic cilia of the upper eyelid have been reported in the literature. ${ }^{14}$ Their origin is not well understood. In the past, they were believed to originate from meibomian glands, which had been completely or partially replaced. ${ }^{6,12}$ Current evidence has suggested their embryological origin, so they should be considered a congenital anomaly whose growth is influenced by various molecules released from the local microenvironment. This hypothesis is strongly supported by their anatomical distribution, because all described cases were situated 

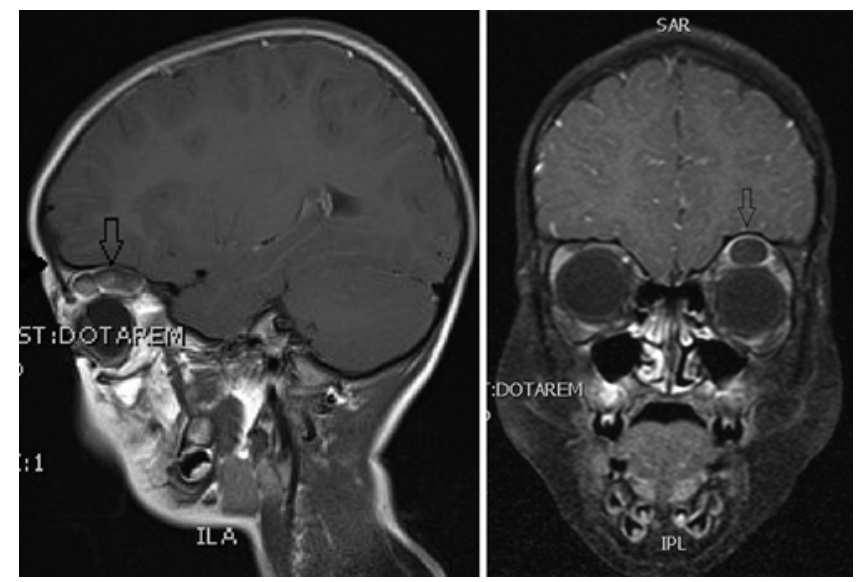

FIG. 4. Sagittal (left) and coronal (right) contrast-enhanced T1-weighted MR images showing a supraorbital extraconal mass just below the roof of the left orbit (arrow).

consistently on the lateral part of the upper eyelid. This localization corresponds embryologically to the watershed area between 2 vascular supplies, the peripheries of the facial and superficial temporal arteries, where a Tessier Type 9 facial cleft is also known to occur. ${ }^{17}$ Morphologically, ectopic cilia are formed by hair with hair bulbs and should be accompanied by sebaceous and sweat glands of the large apocrine type. ${ }^{8}$

In humans, the association of ectopic cilia with only a small number of abnormalities and complications has been documented. Distichiasis and ectopic cilia were reported by Bader. ${ }^{2}$ Gordon et al. ${ }^{10}$ described a complex choristoma of the right eyelid containing ectopic cilia and a functioning aberrant lacrimal gland tissue intermittently producing tears. Sebum that had accumulated at the base of the cilia in 1 patient was found by Chappell et al. ${ }^{5} \mathrm{~A}$ case of ectopic cilia and atopic eczema in the periorbital region ${ }^{18}$ and a hypochromic nevus ${ }^{7}$ were also documented. Edmunds et al. ${ }^{9}$ presented the case of a 2-year-old girl with nail-patella syndrome and ectopic cilia.

Dermoid cysts are the most common orbital cystic tumor presenting in childhood and arise from ectodermal rests pinched off at suture lines during embryogenetic migration. ${ }^{1}$ A dermoid cyst should be differentiated from an atypical epidermoid cyst. ${ }^{22}$ Most orbital dermoid cysts present in childhood as a slow-growing subcutaneous mass near the superotemporal orbit and frontozygomatic suture. When the growth is outward into the eyelid, cysts present in early childhood, and when they grow inward into the orbit, they present later in life. ${ }^{21} \mathrm{~A}$ displacement of the globe could be found in some cases. Deep orbital dermoid cysts may present with proptosis and ocular motility disturbances or orbital nerve compression. Orbital dermoids only rarely form sinus tracts; they can be more commonly found in association with nasal dermoids..$^{15,20}$ Bonavolontà and colleagues ${ }^{4}$ identified only 2 cases with sinus tracts from 145 cases of orbital dermoid cysts examined during a 16-year period. The tracts are not usually to the eyelids, but when they do occur, the sinus tract opening is typically situated in the frontotemporal or orbitotemporal region. Lacey et al. ${ }^{16}$ reported 3 cases of

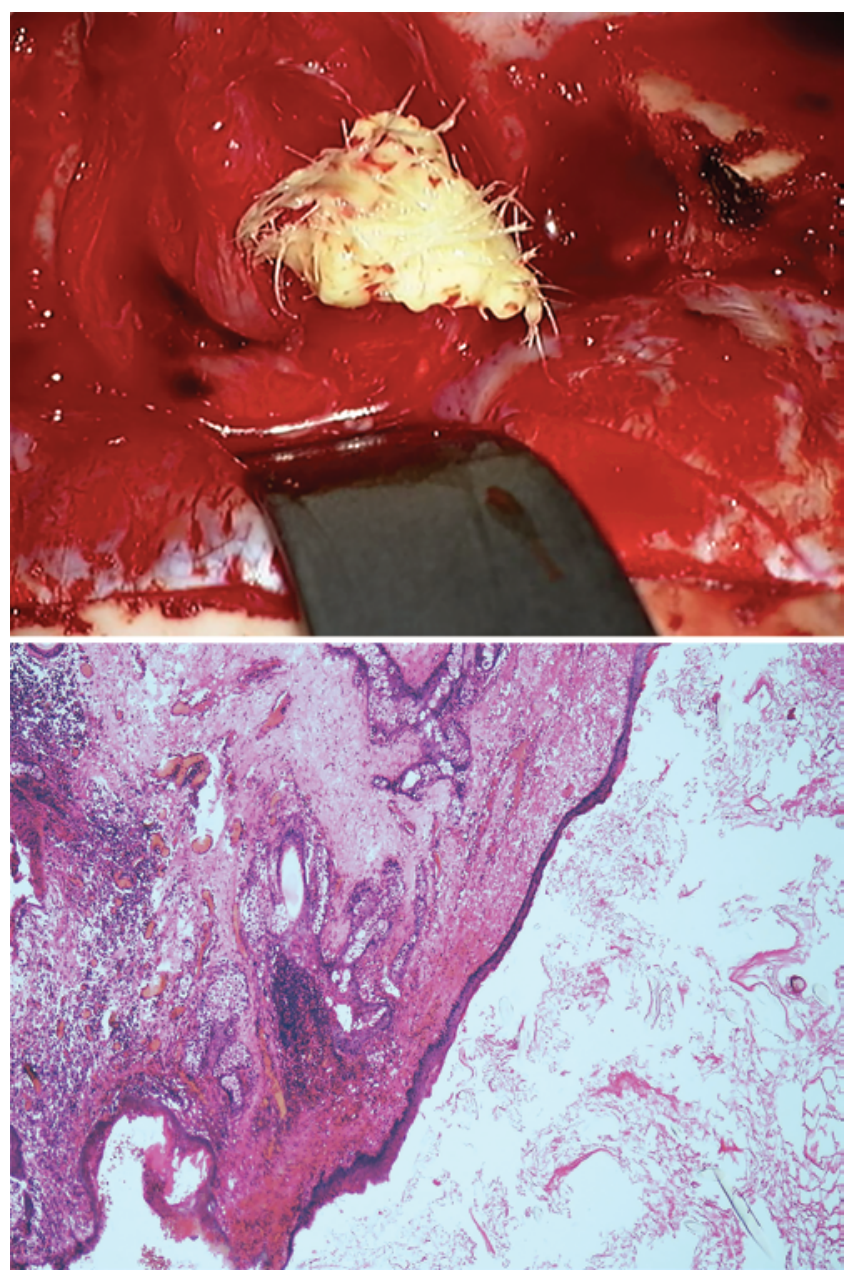

FIG. 5. Gross specimen showing a typical dermoid cyst containing sebaceous glands, hairs, and hair follicles (upper) and a microphotograph of the dermoid cyst (lower) lined by keratinizing squamous epithelium, with multiple adnexal structures in the wall. $\mathrm{H} \& \mathrm{E}$, original magnification $\times 40$. Figure is available in color online only.

orbitotemporal dermoids with a sinus tract and bone invasion. When a sinus tract is present, recurrent infections or intermittent discharge of sebaceous material is common. Orbital cellulitis may also be the presenting sign of an orbital dermoid associated with a sinus tract. However, it is rare for eyelashes or hair to grow from the sinus tract opening. Wells and Harris ${ }^{24}$ reported an orbital dermoid cyst and sinus tract extending from a hypoplastic sphenoid wing, through the lateral orbit, to the skin surface, presenting with acute orbital cellulitis and discharge from the hair-bearing pit above the eyebrow in a 9-month-old infant. Wang et al. ${ }^{23}$ described an orbital dermoid cyst with a sinus tract and hairs mimicking ectopic cilia presenting with episodes of inflammation or infection of the pit, characterized by swelling, redness, a yellowish discharge with a putrid odor, and a slowly growing mass in the upper eyelid in a 2-year-old boy. The whole complex was removed via an infrabrow incision.

In our case, there were no clinical signs of a possible presence of an orbital dermoid or sinus tract before excision of the ectopic cilia, which, as we suppose, was due 
to the deep location of the dermoid cyst. The opening of the sinus tract during the first operation caused discharge of sebaceous material into the soft tissues of the eyelid. If the presence of the orbital dermoid was known, the whole complex could have been removed in a single step in cooperation with a neurosurgeon and an ophthalmologist. Based on our experience, we would like to emphasize that ectopic cilia should be viewed as a developmental disorder that might be associated with other abnormalities. We highly recommend careful clinical and radiological examination in cases of ectopic cilia prior to surgical excision to prevent unnecessary mutilation of the patient.

\section{References}

1. Abou-Rayyah Y, Rose GE, Konrad H, Chawla SJ, Moseley IF: Clinical, radiological and pathological examination of periocular dermoid cysts: evidence of inflammation from an early age. Eye (Lond) 16:507-512, 2002

2. Bader A: Aplasia congenitalis glandularum Meibomi palpebrae inferioris. Graefes Arch Ophthalmol 150:411-413, 1950

3. Baghestani S, Banihashemi SA: Ectopic cilia in a 14-year-old boy. Pediatr Dermatol 28:55-56, 2011

4. Bonavolontà G, Tranfa F, de Conciliis C, Strianese D: Dermoid cysts: 16-year survey. Ophthal Plast Reconstr Surg 11:187-192, 1995

5. Chappell MC, Spencer W, Day SH, Silkiss RZ: Congenital ectopic cilia of the upper eyelid. Ophthal Plast Reconstr Surg 27:e42-e44, 2011

6. Chen TS, Mathes EF, Gilliam AE: "Ectopic eyelashes" (ectopic cilia) in a 2-year-old girl: brief report and discussion of possible embryologic origin. Pediatr Dermatol 24:433-435, 2007

7. da Fonseca FL, Yamanaka PK, Lima PP, Matayoshi S: A 6-year-old girl with ectopic cilia and hypochromic nevus. Clin Ophthalmol 8:1259-1261, 2014

8. Dalgleish R: Ectopic cilia. Br J Ophthalmol 50:592-594, 1966

9. Edmunds MR, Kipioti A, Colloby PS, Reuser TT: A case of ectopic cilia in nail-patella syndrome. Int Ophthalmol 32:289-292, 2012

10. Gordon AJ, Patrinely JR, Knupp JA, Font RL: Complex choristoma of the eyelid containing ectopic cilia and lacrimal gland. Ophthalmology 98:1547-1550, 1991

11. Hase K, Kase S, Noda M, Ohashi T, Shinkuma S, Ishida S: Ectopic cilia: a histopathological study. Case Rep Dermatol 4:37-40, 2012

12. Helper LC, Magrane WG: Ectopic cilia of the canine eyelid. J Small Anim Pract 11:185-189, 1970
13. Jain SC, Saini VK: Bilateral ectopic cilia (a case report). Indian J Ophthalmol 33:67-68, 1985

14. Jakobiec FA, Yoon MK: Histopathologic proof for the origin of ectopic cilia of the eyelid skin. Graefes Arch Clin Exp Ophthalmol 251:985-988, 2013

15. Karandikar M, Yellon RF, Murdoch G, Greene S: Coexistence of dermal sinus tract, dermoid cyst, and encephalocele in a patient presenting with nasal cellulitis. Case report. J Neurosurg Pediatr 11:91-94, 2013

16. Lacey M, Gear AJ, Lee A: Temporal dermoids: three cases and a modified treatment algorithm. Ann Plast Surg 51:103-109, 2003

17. MacQuillan A, Hamilton S, Grobbelaar A: Angiosomes, clefts, and eyelashes. Plast Reconstr Surg 113:1400-1403, 2004

18. Möhrenschlager M, Köhler LD, Ring J: Ectopic cilia in a Caucasian girl with atopic eczema. Acta Derm Venereol 78:146-147, 1998

19. Nakra T, Blaydon SM, Durairaj VD, Shinder R: Congenital upper eyelid ectopic cilia. J Pediatr Ophthalmol Strabismus 48:e16-e18, 2011

20. Rahbar R, Shah P, Mulliken JB, Robson CD, Perez-Atayde AR, Proctor MR, et al: The presentation and management of nasal dermoid: a 30-year experience. Arch Otolaryngol Head Neck Surg 129:464-471, 2003

21. Rao AA, Naheedy JH, Chen JYY, Robbins SL, Ramkumar HL: A clinical update and radiologic review of pediatric orbital and ocular tumors. J Oncol 2013:975908, 2013

22. Ren X, Lin S, Wang Z, Luo L, Jiang Z, Sui D, et al: Clinical, radiological, and pathological features of 24 atypical intracranial epidermoid cysts. J Neurosurg 116:611-621, 2012

23. Wang Y, Su F, Li Y, Xiao L: Orbital dermoid cyst with sinus tract mimicking ectopic cilia. J AAPOS 14:532-533, 2010

24. Wells TS, Harris GJ: Orbital dermoid cyst and sinus tract presenting with acute infection. Ophthal Plast Reconstr Surg 20:465-467, 2004

25. Wiegmann E: Eine Zilie an einem ungewohnlichen Platz, im Knorpel des Oberlides. Klin Monatsbl Augenheilkd 96:230-231, 1936

\section{Author Contributions}

Conception and design: Krahulík, Karhanová. Acquisition of data: Krahulík, Karhanová. Analysis and interpretation of data: Krahulík, Karhanová, Brychtová. Drafting the article: Krahulík. Critically revising the article: all authors. Approved the final version of the manuscript on behalf of all authors: Krahulík.

\section{Correspondence}

David Krahulík, Department of Neurosurgery, University Hospital Olomouc, I. P. Pavlova 6, 77900 Olomouc, Czech Republic.email: david.krahulik@fnol.cz. 